\title{
Serum zinc values in children with congenital heart disease
}

\author{
*Sadoh WE, Sadoh AE \\ Department of Child Health, University of Benin/ University of Benin Teaching Hospital, PMB 1111, \\ Benin City, Nigeria
}

\begin{abstract}
Background: Some children with congenital heart diseases (CHD) may have increased pulmonary blood flow that causes recurrent bronchopneumonia and congestive heart failure. Serum zinc is reduced in children with pneumonia and patients on diuretics.

Objective: To evaluate the serum zinc level of children with CHD and their controls without CHD.

Method: The subjects were 41 children with CHD confirmed on echocardiography recruited from a paediatric cardiology clinic in a tertiary centre in Nigeria. The controls were 41 children without CHD. Biodata and anthropometric measurements were taken. The serum zinc was determined using atomic absorption spectrophotometer method.

Result: The mean difference in the serum zinc of the subjects $101.3 \pm 21.6 \mu \mathrm{g} / \mathrm{dl}$ and controls $106.5 \pm 18.3 \mu \mathrm{g} / \mathrm{dl}$, was not significant, $\mathrm{p}=0.351$. The subjects with pneumonia had a lower mean serum zinc value $89.5 \pm 15.0 \mu \mathrm{g} / \mathrm{dl}$ compared to those without pneumonia $103.9 \pm 22.2 \mu \mathrm{g} / \mathrm{dl}, \mathrm{p}=0.006$. The mean serum zinc values of the subjects on diuretic was not statistically different from those not on diuretic, $\mathrm{p}=0.599$.

Conclusion: The serum zinc levels of the subjects and controls were not significantly different. Children with CHD and pneumonia had significantly lower zinc level compared to those without pneumonia.

Keywords: congenital heart disease, diuretic, pneumonia, zinc.

African Health Sciences 2013; 13(3): 601 - 606 http://dx.doi.org/10.4314/ahs.v13i3.12
\end{abstract}

\section{Introduction}

Congenital heart diseases (CHD) are the commonest congenital anomalies accounting for 8/1000 live births globally ${ }^{1}$ and $6-8 / 1000$ live births in children in Nigeria ${ }^{2}$. They are a cause of chronic ill health and a significant cause of mortality in children especially in developing countries where there are non-existent or limited capacity for surgical and percutanoeus interventions ${ }^{3,4}$.

Zinc an intracellular ion which is an antioxidant, is essential for the activity of many enzymes such as angiotensin converting enzyme and the matrix metalloproteinases 5 . Zinc has been shown to be involved in growth and development; its deficiency is associated with higher prevalence of pneumonia ${ }^{6}$ and diarrhea ${ }^{7}$ in children while pregnant mothers deficient in zinc have been shown to have a higher prevalence of babies with $\mathrm{CHD}^{8}$.

The CHD with left to right shunt are associated with pulmonary overcirculation. This

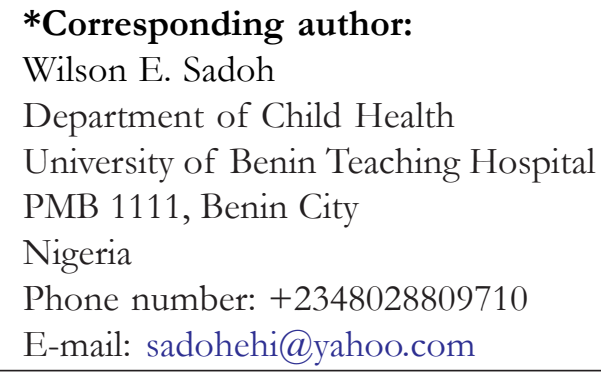

predisposes to recurrent bronchopneumonia and congestive heart failure $(\mathrm{CHF})^{9}$. The septal defects such as ventricular septal defect (VSD), atrioventricular septal defect (AVSD) and Patent ductus arteriosus (PDA) are examples of such anomaly. Bronchopneumonia and CHF may affect serum zinc level in several ways; studies have shown that children with pneumonia have significantly lower serum zinc values compared to their counterparts without pneumonia ${ }^{6,10}$. The diuretic therapy in patients with heart failure causes zincuria ${ }^{11}$. The thiazide and angiotensin converting enzyme inhibitors are more likely to cause zincuria than other medicines used for $\mathrm{CHF}^{12,13}$.

In resource poor countries, because the capacity for surgical interventions for children with CHD is limited, most of these children live with chronic heart failure and the recurrent bronchopneumonia which may predispose them to zinc depletion. Recurrent episodes of bronchopneumonia may cause low zinc and the low zinc levels may further predispose to bronchopneumonia setting up a vicious circle. Besides, children with CHD are prone to low serum zinc levels because of poor intake and absorption arising from malnutrition which they are prone to ${ }^{14}$.

As part of the management of these patients with CHD who also have chronic heart failure and 
recurrent pneumonia, they are placed on anti-failure medications involving diuretics and ACE inhibitors. Recurrent antibiotic treatment amongst other medicines is also required. The cost of these medicines has been shown to be a cause of socioeconomic burden to their parents ${ }^{15}$.

This study was undertaken to evaluate the serum zinc level in children with CHD compared to age and sex matched controls without CHD. The study also seeks to identify factors influencing serum zinc levels in these children.

\section{Methods}

The study was carried out in the Paediatric Cardiology out- patient clinic of a tertiary hospital in Nigeria. A convenient sample size of 41 subjects and 41 controls were recruited. The subjects were clinically stable children with congenital heart disease (CHD) attending the clinic with an inclusion criterion that the last febrile illness was at least two weeks before the day of recruitment. Serum zinc levels are low following febrile illnesses. An informed verbal consent was obtained from the accompanying parent(s). The diagnosis of the CHD was made on clinical ground, typical findings on chest radiograph and electrocardiogram. The diagnosis was confirmed on echocardiography done by one of the investigators (WES). The controls were age and sex matched children who either attended or accompanied their parents to the immunization clinic and patients who were followed up in the clinics for febrile illnesses (malaria, pharyngitis and acute otitis media). In all cases, any febrile illness would have resolved at least two weeks prior to the day of recruitment. The children had a thorough systemic examination particularly looking for signs of CHD such as finger clubbing, cyanosis, suffused conjunctivae, abnormal heart sound (such as fixed and wide splitting of the second heart sound) and presence of murmur. The controls had echocardiography to exclude CHD.

Patients in the clinic with chronic heart failure are placed on hydrochlorthiazide and spironolactone. Captopril and Digoxin were included in severe cases. These patients also received antibiotic when they had pneumonia. Patients with TOF are placed on propanolol. All the patients are seen from monthly clinic schedule to other time interval as deemed appropriate. Other treatments were offered as required. The study was carried out between March and August 2011.
A proforma was used to collect information on biodata, socioeconomic class (SEC) and the presence and time since last febrile illness. The SEC was determined by the methods described by Olusanya et $\mathrm{al}^{16}$. The drug profile of the patients on medicines for heart failure and the occurrence of bronchopneumonia (including frequency) were determined from review of the casenotes. It was noted if the patient had cyanotic or acyanotic CHD.

The patients' weight was measured using a bassinet weighing scale for infant and an appropriate weighing scale for older children, the height/ length was measured with a standiometer or an infantometer as appropriate, using standard methods. The $\mathrm{Z}$ scores of the weight for age were computed using the WHO growth charts for children ${ }^{17}$. Malnutrition was defined using the $Z$ scores of weight for age thus; children with $z$ scores $<-2$ SD were malnourished, well nourished children were those with $\mathrm{Z}$ score between -2 and +2 SD and overweight children had $z$ scores $>+2$ SD.

Following aseptic procedure, $3 \mathrm{ml}$ of blood was drawn from each patient, it was spun, the serum decanted and stored in a refrigerator at a temperature of $-40^{\circ}$. Once recruitment was completed, the serum samples were prepared for serum Zinc analysis using the modified Dogan el al method ${ }^{18}$. The serum Zinc was then analyzed for using atomic absorption spectrophotometer (AAS, Varian Spectra AA10 model). Three separate analyses for Zinc were done on each sample and the mean of the three Zinc values was recorded.

Ethical approval was obtained from the University Of Benin Teaching Hospital Ethics Committee.

\section{Statistical analysis}

The data were entered into an SPSS spread sheet and analyzed with SPSS version 16.0. IL Chicago. The means of continuous variable such as age, weight, height and serum $\mathrm{Zn}$ were compared with student's t test, multiple means were compared with one way ANOVA. The association between non parametric variables was tested with Pearson's chi square test. Statistically significant $\mathrm{p}$ value was taken as $<0.05$.

\section{Results}

There were 41 subjects with congenital heart disease recruited for the study with 41 age and sex matched controls. There were 21(51.2\%) males and 20(48.8\%) females each of subjects and controls. The ages for 
the subjects and control ranged between 6 weeks and 17 years. The subjects were further classified into age groups thus; $<1$ year $11(26.8 \%), 1-<5$ years $21(51.2 \%), 5-<10$ years $5(12.2 \%)$ and $>10$ years $4(9.8 \%)$. The mean age, weight and height of the subjects were not significantly different from those of the controls. The details of the study characteristics are shown in table I. Two subjects did not have enough information to assess their socioeconomic status. The distribution of the subjects and controls by their socioeconomic classes are shown in table 1.
$100.7 \pm 19.6$ and $97.4 \pm 16.3 \mu / \mathrm{dl}$ respectively. The differences in the mean serum zinc values were however not statistically significant, $\mathrm{p}=0.932$.

The mean $\mathrm{Zn}$ levels in subjects who had bronchopneumonia $89.5 \pm 15.0 \mu \mathrm{g} / \mathrm{dl}$ was significantly lower than the value obtained in subjects who did not have bronchopneumonia $103.9 \pm 22.2$ $\mu \mathrm{g} / \mathrm{dl}, \mathrm{p}=0.0006$. There was no significant gender and socioeconomic class differences in the mean $\mathrm{Zn}$

Table 1: Characteristics of the study population

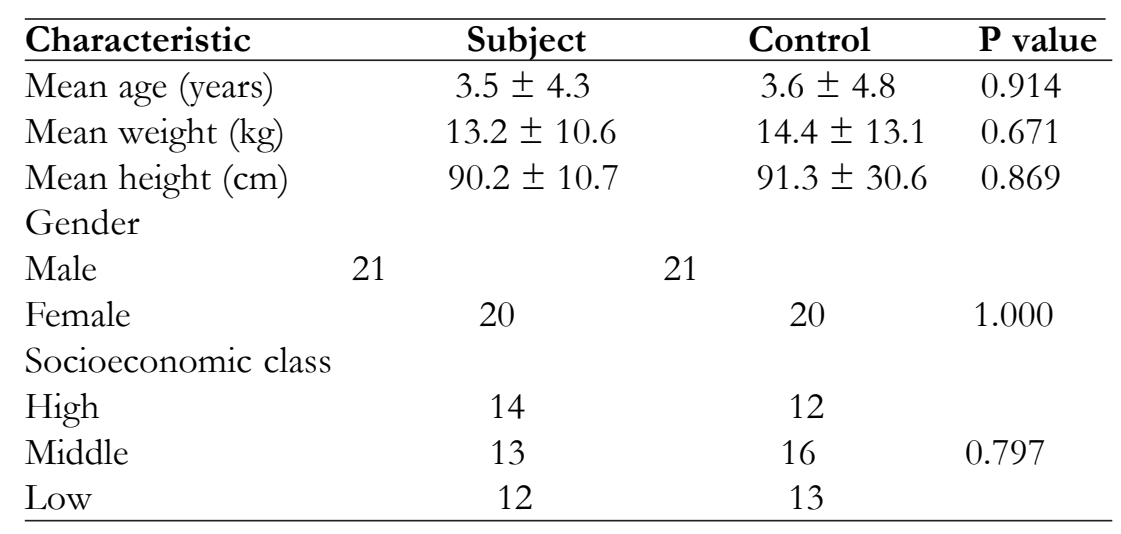

Thirty one $(75.6 \%)$ of the subjects had acyanotic CHD while $10(23.4 \%)$ had cyanotic CHD. The diagnoses of the subjects are shown in table 2 . Ventricular septal defect either isolated or in combination with other cardiac defects $22(53.6 \%)$ was the commonest acyanotic CHD while Tetralogy of Fallot $7(17.1 \%)$ was the commonest cyanotic CHD. There were 10(24.4\%) subjects who were in chronic heart failure and were thus on diuretics, $3(30 \%)$ of those on diuretic were also on digoxin and captopril. Seventeen (41.5\%) subjects had had bronchopneumonia. The distribution of bronchopneumonia episodes since birth showed that $7(41.2 \%), 4(23.5 \%), 4(23.5 \%)$ and $2(11.8 \%)$ of the 17 children had had bronchopneumonia once, twice, four times and thrice times respectively. Of those with bronchopneumonia, 1(5.9 \%) had cyanotic CHD (truncus arteriosus) while 16(94.1\%) had acyanotic CHD.

The mean $\mathrm{Zn}$ level in the subjects was 101.3 $\pm 21.6 \mu \mathrm{g} / \mathrm{dl}$ with a range of $67.3-156.2 \mu \mathrm{g} / \mathrm{dl}$. This was not statistically different from the mean level in the control 106.5 \pm 18.3 (range 69.9-139.9) $\mu \mathrm{g} / \mathrm{dl}, \mathrm{p}=0.351$. The mean serum zinc level was highest $102.6 \pm 30.7 \mu \mathrm{g} / \mathrm{dl}$ in youngest age group $<$ 1 year and lowest $94.8 \pm 12.4 \mu \mathrm{g} / \mathrm{dl}$ in the oldest age group $>10$ years. The mean serum zinc values of subjects aged $1-<5$ year and $5-<10$ years were

African Health Sciences Vol 13 Issue 3 September 2013 levels of subjects, $\mathrm{p}=0.937$ and $\mathrm{p}=0.754$ respectively. The mean serum $\mathrm{Zn}$ levels of subjects who were on diuretic for chronic heart failure and those not on diuretic was not statistically different, $\mathrm{p}$ $=0.599$. Although subjects who were malnourished had lower mean serum $\mathrm{Zn}$ value $95.4 \pm 24.8 \mu \mathrm{g} / \mathrm{dl}$, than those with normal nutritional status, the difference was not statistically significant, $\mathrm{p}=0.654$. Table 3 shows the mean $\mathrm{Zn}$ levels according to the subjects socio-demographic and clinical characteristics.

Table 2: Type of congenital heart disease in subjects

\begin{tabular}{lcc}
\hline Type of CHD & Number & $\mathbf{\%}$ \\
\hline Isolated VSD & 19 & 46.3 \\
VSD and ASD & 1 & 2.4 \\
VSD and PDA & 2 & 4.9 \\
TOF & 7 & 17.1 \\
AVSD & 5 & 12.2 \\
Isolated ASD & 3 & 7.4 \\
TA & 2 & 4.9 \\
TGA & 1 & 2.4 \\
Isolated PDA & 1 & 2.4 \\
\hline
\end{tabular}

VSD = ventricular septal defect, ASD = atrial septal defect, $\mathrm{PDA}=$ patent ductus arteriosus, $\mathrm{TOF}=$ tetralogy of Fallot, AVSD = atrio-ventricular septal defect, $\mathrm{TA}=$ truncus arteriosus and $\mathrm{TGA}=$ transposition of great arteries. 
Table 3: Mean serum zinc values of subjects by some socio-demographic and clinical characteristics

\begin{tabular}{lcc}
\hline Characteristics & Mean Zinc $(\mu \mathrm{g} / \mathrm{dl})$ & p value \\
\hline Gender & $98.0 \pm 23.5$ & \\
Males & $98.7 \pm 19.0$ & 0.937 \\
$\begin{array}{l}\text { Females } \\
\text { Type of CHD }\end{array}$ & \\
$\begin{array}{l}\text { Cyanotic } \\
\text { Acyanotic } \\
\text { Bronchopneumonia }\end{array}$ & $91.5 \pm 19.0$ & \\
$\begin{array}{l}\text { Present } \\
\text { Absent }\end{array}$ & $89.5 \pm 15.0$ & 0.144 \\
$\begin{array}{l}\text { Diuretic therapy } \\
\text { On diuretic }\end{array}$ & $103.9 \pm 22.2$ & 0.0006 \\
Not on diuretic & $95.4 \pm 17.0$ & \\
$\begin{array}{l}\text { Nutritional status } \\
\text { Malnutrition }\end{array}$ & $100.0 \pm 22.9$ & 0.599 \\
$\begin{array}{l}\text { Normal nutritional status } \\
\text { Socioeconomic class }\end{array}$ & $95.4 \pm 24.8 \pm 19.6$ & \\
High SEC & $95.4 \pm 14.4$ & \\
Middle SEC & $102.6 \pm 25.5$ & 0.654 \\
Low SEC & $99.3 \pm 27.5$ & \\
\hline
\end{tabular}

Table 4 shows the mean serum zinc levels by type of CHD. The lowest value was obtained in patients with Truncus arteriosus $80.4 \pm 13.1 \mu \mathrm{g} / \mathrm{dl}$ and the highest was in atrio-ventricular septal defect $105.9 \pm$ $41.2 \mu \mathrm{g} / \mathrm{dl}$. There is no significant correlation between the subjects' age, height and weight with the serum $\mathrm{Zn}$ values. $(\mathrm{r}=-0.059, \mathrm{p}=0.727 ; \mathrm{r}=$ $0.07, \mathrm{p}=0.679 ; \mathrm{r}=-0.114, \mathrm{p}=0.502$ respectively) No correlation was noted for the controls with respect to age height and weight.

Table 4: The mean serum zinc values of the different congenital heart diseases

\begin{tabular}{ll}
\hline Type of CHD (n) & Mean $\mathbf{Z n ~ l e v e l ~}(\boldsymbol{\mu g} / \mathbf{d l})$ \\
\hline Isolated and combined VSD (24) & $103.9 \pm 19.0$ \\
TOF and TGA (8) & $94.8 \pm 19.6$ \\
AVSD (4) & $105.9 \pm 41.2$ \\
ASD (3) & $98.0 \pm 15.0$ \\
TA (2) & $80.4 \pm 13.1$ \\
\hline
\end{tabular}

\section{Discussion}

The subjects who had bronchopneumonia had significantly lower zinc values compared to those who did not have bronchopneumonia. Considering that zinc level was determined in these children after their zinc status should have normalized, the findings in this study highlights the role zinc plays in acting as acute phase reactant in bronchopneumonia thus leading to its depletion in children with CHD and pneumonia. In a Turkish study ${ }^{6}$, children younger than two years with pneumonia had significantly lower serum zinc than their aged matched control without pneumonia. Kumar et $\mathrm{al}^{19}$ in India, showed that the blood zinc level of children with severe pneumonia was significantly lower than age, sex and nutritional status matched controls. CHD patients with pneumonia may thus be particularly susceptible to zinc depletion even after they are supposed to have recovered from acute pneumonia.

The subjects on diuretic for the treatment of chronic CHF had lower serum zinc values compared to subjects who were not on diuretic. The difference did not reach statistical significance. This is consistent with some studies that did not show any significant difference in the serum zinc level of volunteers on frusemide and hydrochlorthiazide ${ }^{12,20}$. However, the serum zinc levels of children with

African Health Sciences Vol 13 Issue 3 September 2013 
congestive heart failure was found to be significantly lower than their age and sex matched controls in a study by Atlihan and co-workers ${ }^{20}$. The difference in findings in the two studies may be due to patients characteristics, the patients in the Atlihan study, were recruited during the acute phase of heart failure while in the present study the children were evaluated at least two weeks after the acute heart failure episode. This would have allowed time for the partial restoration of zinc in patients in the present study. The lower zinc levels in patients with cardiac failure can be attributed to the zincuric effect of the diuretic use. The patients in this study were on hydrochlorthiazide and spiranolactone. Although thiazide therapy is associated with zinc depletion; that some patients were also on digoxin may have mitigated the zincuria effect of the diuretics. The reversal of zinc depletion by digoxin was demonstrated in a study on children with heart failure. The lower serum zinc level initially noted in patients with heart failure when compared to their controls increased significantly following digoxin therapy ${ }^{21}$.

Another medicine that would have accentuated the zinc depletion in the management of CHF is the ACE inhibitor captopril. Most of the patients were not on captopril (this was prior to the inclusion of ACE inhibitor to the treatment of CCF as standard practice in the centre) and the additional zinc depletion from this medicine could not be evaluated. Captopril is particularly associated with zinc depletion because zinc is an important coenzyme in the activity of angiotensin converting enzyme. To properly evaluate the effect of diuretic therapy and ACE inhibitor, a controlled study involving children with chronic heart failure on medication for a long duration perhaps may yield more inferences.

The distribution of the malnourished and well nourished children in both the subjects and controls was not significantly different. Thus the differences noted in the serum zinc values among subject with and without certain characteristics may not have been due to the well known effect of malnutrition on serum zinc status of the study subjects $^{22}$. It is of note that all the children including the malnourished ones had normal serum zinc levels. It is possible that sources of zinc in their diet are common to both children with CHD and those without CHD. The local cereals that the under-fives are fed are commonly fortified with groundnut, a good source of zinc.
From the study, cyanotic CHD subjects had a higher serum zinc level compared to those with acyanotic CHD. This result could be due to the very low serum zinc values obtained in the patients with truncus arteriosus who had the lowest serum zinc levels compared to the other CHDs. This may have contributed to the lower serum zinc value in Cyanotic CHD. Truncus arteriosus is a cyanotic CHD with increased pulmonary overcirculation and thus prone to bronchopneumonia and CHF. In fact the two patients with truncus arteriosus had $3-4$ episodes of bronchopneumonia prior to the study and were being managed for chronic CHF. This finding again underscores the fact that associated bronchopneumonia is a major contributor to the low zinc values obtained in these patients compared to the value in patients with other types of CHDs.

\section{Conclusion}

The serum zinc level of children with CHD was not significantly lower than in controls. The presence of acute bronchopneumonia in children with CHD and the presence of truncus arteriosus were associated with zinc reduction in this study.

\section{Reference}

1 Ferencz C, Rubin JD, McCarter RJ, Brenner JI, Neill CA, Perry LW et al. Congenital heart disease. Prevalence at live birth. The Baltimore-Washington infant study. Am J Epidemiol 1985;121:31-6

2 Gupta B, Antia AU. Incidence of congenital heart disease in Nigeria children. Brit heart J 1967; 29: 906 - 9

3 Jaiyesimi F. Congenital cardiac malformation: a serious health problem in Nigeria? Nig J Paediatr 1982; 9: 67-70

4 Nte AR, Yarhere I, Fiebai P. Paediatric mortality: a review of causes among admissions at the University of Port Harcourt Teaching Hospital (January 2003 - December 2005). Nig J Paediatr 2006; 33: 90-8

5 King JC, Cousins RJ. Zinc. In: Shils ME, Shike M, Ross CA, Caballero B, Cousins RJ, editors Modern Nutrition in health and disease, $10^{\text {th }}$ edn. Philadelphia: Lippincott Williams \& Wilkins 2005, p. $271-85$

6 Arica S, Arica V, Dag H, Kaya A, Hatipoglu S, Fenercioglu A, et al. Serum zinc levels in children 
of $0-24$ months diagnosed with pneumonia admitted to our clinic. Int Clin Exp Med 2011; 4: $227-33$

7 Sazawal S, Black R, Bhan M, Bhandari N, Sinha A, Jalla $S$. Zinc supplementation in young children with acute diarrhea in India. $N$ Engl J Med 1995; 333: 839 - 44

8 Caulfield LE, Zavaleta N, Shankar AH, Merialdi M. Potential contribution of maternal zinc supplementation during pregnancy to maternal and child survival. Am J Clin Nutr 1998; 68: 499 $-508$

9 Sadoh WE. Natural history of ventricular septal defect in Nigerian children. South Afr J Child Hlth 2010; 4: $16-9$

10 Brooks WA, Yunus M, Santosham m, Wahed MA. Zinc for severe pneumonia in very young children: double-blind placebo controlled trial. Lancet 2004; 22: 363: $1683-8$

11 Reyes AJ, Olhaberry JV, Leary WP, Lockett CJ, Alcocer L. Diuretic and zinc. S Afr Med J 1982; 62: $373-41$

12 Leary WP, Reyes AJ, Wynne RD, van Der Byl K. Renal excretory actions of furosemide, of hydrochlorthiazide and of the vasodilator flosequinan in healthy subjects. J Int Med Res 1990; 18: $120-41$

13 Abu-Hamdan DK, Desai H, Sondheimer J, Felietta J, Mahajan S, McDonald F. Taste acuity and zinc metabolism in captopril treated hypertensive male patients. Am J Hypertens 1988; 1: $303 \mathrm{~S}-8 \mathrm{~S}$
14 King JC, Assessment of techniques for determining human zinc requirements. $J$ Am Diet Assoc 1986; 86: 1523 - 8

15 Sadoh WE, Nwaneri DU, Owobo AC. The cost of out-patinet management of chronic heart failure in children with congenital heart disease. Nig J Clin Pract 2011; 14: 65 - 9

16 Olusanya O, Okpere E, Ezimokhai M. The importance of socioeconomic class in voluntary fertility control in a developing country $W$ Afri J Med 1985; 4: 205 - 12

17 WHO. Child growth standards. Found at www.who.int/entity/childgrowth/standards/ (Assessed January 2011)

18 Dogan P, Dogan M, Klockenkamper R. Determination of trace elements in blood serum of patients with Behcet disease by total reflection $\mathrm{X}$ ray florescence analysis. Clin Chem 1993; 39: $1037-41$

19 Kumar S, Awasthi S, Jain A, Srivastava RC. Blood Zinc levels in children hospitalized with severe pneumonia: a case control study. Indian Pediatr 2004; 41: 486 - 91

20 Wester PO. Urinary zinc excretion during treatment with different diuretics. Acta Med Scand 1980; 208: $209-12$

21 Atlihan F, Soyelemezoglu T, Gokce A, Guvendik $\mathrm{G}$, Saticio O. Zinc and copper in congestive heart failure. Turk J Pediatr 1990; 32: 33 - 8

22 Sandstead HH. Zinc deficiency. A public health problem? Am J Dis Child 1991; 145: 853 - 9 